\title{
Soy isoflavone intake and the likelihood of ever becoming a mother: the Adventist Health Study-2
}

This article was published in the following Dove Press journal:

International Journal of Women's Health

5 April 2014

Number of times this article has been viewed

\author{
Bjarne K Jacobsen' \\ Karen Jaceldo-Siegl ${ }^{2}$ \\ Synnøve F Knutsen ${ }^{2}$ \\ Jing Fan $^{2}$ \\ Keiji Oda ${ }^{2}$ \\ Gary E Fraser ${ }^{2}$ \\ 'Department of Community \\ Medicine, University of Troms $\varnothing$, \\ Tromsø, Norway; ${ }^{2}$ Department \\ of Epidemiology, Biostatistics \\ and Population Medicine, School \\ of Public Health, Loma Linda \\ University, Loma Linda, CA, USA
}

Correspondence: Bjarne K Jacobsen Department of Community Medicine, Faculty of Health Sciences, University of Troms $\varnothing$, MH-building, N-9037 Tromsø, Norway

Tel +47 77644833

Fax +47 77644831

Email bjarne.jacobsen@uit.no
Objectives: As little is known about the possible relationship between the intake of phytoestrogens and female fertility, we investigated the relationship between soy isoflavone intake and the risk of nulliparity and nulligravidity.

Methods: A cross-sectional study of 11,688 North American Adventist women aged 30-50 years old with data regarding childbearing. These women were, as a group, characterized by a high proportion (54\%) of vegetarians and a healthy lifestyle with a very low prevalence of smoking and alcohol use.

Results: The mean isoflavone intake (17.9 mg per day) was very high compared to other Western populations. Only $6 \%$ of the women indicated no intake of isoflavones. We found, after adjustment for age, marital status, and educational level, an inverse relationship $(P=0.05)$ between isoflavone intake and the likelihood of ever having become a mother. In women with high ( $\geq 40 \mathrm{mg} /$ day) isoflavone intake (12\% of this group of women), the adjusted lifetime probability of giving birth to a live child was reduced by approximately $3 \%(95 \% \mathrm{CI}: 0,7)$ compared to women with low ( $<10 \mathrm{mg} /$ day) intake. No relationships were found between the isoflavone intake and parity or age at first delivery in parous women. A similar inverse relationship $(P=0.03)$ was found between the isoflavone intake and the risk of nulligravidity with a $13 \%(95 \% \mathrm{CI}: 2,26)$ higher risk of never have been pregnant in women with high ( $\geq 40 \mathrm{mg} /$ day) isoflavone intake. These relationships were found mainly in women who reported problems becoming pregnant.

Conclusion: The findings suggest that a high dietary isoflavone intake may have significant impact on fertility.

Keywords: soybeans, phytoestrogens, isoflavones, fertility, Seventh-Day Adventist

\section{Introduction}

Soy products are often considered a healthy alternative to meat. Some studies suggest that phytoestrogen isoflavones in the diet (for which soy products are the major source) have beneficial effects on cardiovascular diseases, osteoporosis, cancer, and menopausal

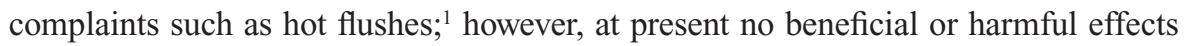
associated with isoflavones in the diet have been clearly established. ${ }^{2,3}$ The three major isoflavones in soy products are the glycosides daidzin, genistin, and glycitin. ${ }^{4}$

Isoflavone intake is much higher in Asian cultures (typically $40 \mathrm{mg} /$ day in older adults in Japan and the People's Republic of China) than in most Western populations (typically $<3 \mathrm{mg} /$ day). ${ }^{5}$ The mean intake in postmenopausal women in the Framingham study was estimated to be only $154 \mu \mathrm{g} /$ day $^{6}$; an even lower value ( $59 \mu \mathrm{g} /$ day) was recently reported for women of reproductive age in the US. ${ }^{7}$

Isoflavones bind to and activate estrogen receptors and there is a large amount of literature concerning possible reproductive effects of isoflavones in animal models; ${ }^{8}$ 
isoflavones in large doses have been found to hamper fertility in animals. ${ }^{9}$ There has also been some interest concerning the impact of isoflavones on reproductive health in humans. These include possible short- and long-term effects of the extremely high blood concentration of isoflavones in infants fed soy-based formula. ${ }^{10}$

There is little evidence from clinical studies of humans that soy protein and isoflavones have a major effect on sex hormone concentrations in women, although data from premenopausal women have indicated reduced follicle stimulating hormone and luteinizing hormone, and increased cycle length in women exposed to soy isoflavones. ${ }^{11}$ Results regarding soy consumption and age at puberty in girls differ between studies. $^{12}$

A meta-analysis of 92 randomized trials did not reveal more side effects (including gynecological problems) in women who received phytoestrogens compared to those in a control group. ${ }^{13}$ There are a few reports of patients with extremely high consumption of soy products and significant nonmalignant uterine pathology. ${ }^{14,15}$ Lower, but still quite high isoflavone doses (150 mg of isoflavones per day), during a 5 -year period have been found to increase endometrial hyperplasia; ${ }^{16}$ an informal review indicated that more than $70 \mathrm{mg}$ of isoflavones per day may be associated with endometrial bleeding in postmenopausal women. ${ }^{17}$ However, there is no evidence for a higher risk of endometrial cancer in women with a high dietary soy intake. ${ }^{18,19}$

There are some indications that supplementing with high doses (1,500 mg daily) of soy isoflavones may be beneficial in in vitro fertilization treatment, ${ }^{20}$ but there is a need for studies looking at the relationship between dietary soy isoflavone intake and nulliparity or null gravidity within a diverse population.

The aim of this study was therefore to study the relationships between the intake of soy isoflavones and the likelihood of ever becoming pregnant and delivering at least one live child. This was investigated in a population with a relatively high proportion of strict vegetarians (vegans) as well as subjects who were nonvegetarian. The population has, in a Western context, a very high consumption of soy isoflavones and is also characterized by a large variation in intake.

\section{Material and methods}

Adventist church members living in the USA and Canada, aged 30 years and older, were included in the Adventist Health Study-2 (AHS-2) from 2002 to 2007. More than 96,000 participants completed a lifestyle questionnaire. The Adventist church encourages a healthy lifestyle with no smoking and alcohol consumption and advises members to follow a vegetarian diet. ${ }^{21}$

The comprehensive self-administered questionnaire included sections for marital status, ethnic group, medical history, smoking history, present and past use of alcohol, physical activity, diet (food frequency), supplement use, and vegetarian food consumption.

The female history section included information about, among other things, menarche, menstruation (including irregularities), difficulties in becoming pregnant (1 straight year or more without success to become pregnant), whether the women had ever been pregnant and the outcome of the pregnancies (miscarriages or stillbirths, ectopic pregnancies, elective abortion, live births), age at each delivery of a live child, and the use of oral contraceptives. There were also questions about current weight and height, as well as weight when aged 20. ${ }^{22,23}$ Body mass index (BMI) was computed as weight in kilograms divided by the square of height in meters $\left(\mathrm{kg} / \mathrm{m}^{2}\right)$.

\section{Assessment of diet, vegetarian status, and the intake of soy isoflavones}

The food frequency questionnaire (FFQ) was validated against six 24-hour dietary recalls for intake of nutrients ${ }^{24}$ and selected foods and food groups. ${ }^{25}$ In the present study, dietary intake was assessed from FFQ data. Vegetarian status was determined according to the reported intake of foods of animal origin. Nonvegetarians ate non-fish meats at least once per month and all meats combined (fish included) more than once per week with no restrictions on dairy. Vegans, who constituted a subgroup of the vegetarians, ate all types of meat, fish/eggs and dairy less than once per month. ${ }^{26}$

The FFQ includes several items to assess soy intake: 34 commercially prepared vegetarian meat analogs; 15 soy beverages; and one tofu/soybean product. Isoflavone content was based on the Nutrition Data System for Research 2008 database (The Nutrition Coordinating Center, Minneapolis, MN, USA), an analytic database of over 20,000 foods updated annually while maintaining nutrient composition true to the version at data collection. ${ }^{27}$ Recipes were created for foods not in the Nutrition Data System database, such as homemade vegetarian dishes, soy milk, and commercial meat analogs. Nutrient information pertaining to such foods was obtained from the US Department of Agriculture, manufacturers, and other published data.

The intake (I) of soy isoflavones daidzein, genistein, and glyceitin (in aglycone equivalent weights) was computed 
using the product-sum method. ${ }^{28}$ Thus, I = sum (weighted frequency of use of a food $\times$ weighted portion size consumed of that food $\times$ amount of isoflavone in a standard serving size of that food). The intake of vegetarian meat analogs, tofu/soybean products, and soy milk were computed the same way. Intake of soy protein according to the FFQ was highly correlated ( $r=0.8$ ) to the intake according to six 24-hour dietary recalls and was also correlated $(r=0.5)$ to the total isoflavonoids in urine. ${ }^{29}$

\section{Analytical cohorts}

Two subgroups of women from the AHS-2 study population were included in the present analyses. In addition to information about isoflavone intake, we required both groups to provide information about marital status, level of education, parity, age at first delivery (if parous), and that they had also identified as Adventists when they were 15-25-years-old.

The first group of women included the 4,476 youngest women in the AHS-2 population - women aged 30-40 years at enrollment. As women aged 30-40 are still of childbearing age, data from this group of women do not represent the total reproductive history of the women. Therefore, in order to evaluate the relationships between isoflavone intake and childbearing when the childbearing period for all practical purposes had ended, we also selected a second group of 7,212 women aged $41-50$ years. Less than $0.5 \%$ of the women in the AHS-2 population stated that their first birth was at age 41 or later. The age was capped at 50 years to minimize time lapses between dietary habits at study baseline and those during childbearing years.

\section{Statistical analyses}

The statistical analyses included simple cross-tabulations, analyses of variance, and correlation, as well as Cox regression and a log-binomial model. Isoflavone intake was categorized into six groups $(0-9,10-19,20-29,30-39$, 40-49, and $50 \mathrm{mg}$ or more per day).

Cox regression analyses were performed when analyzing data from women aged 30-40 years. We applied a Cox-regression model with age as the time variable starting at age 14 (as this was the lowest age at first delivery registered in the cohort); we then "followed" this retrospective cohort till age at enrollment in the AHS-2, using historical data. Interaction terms between all independent variables and age were included due to violation of the proportional hazard assumption. A woman was considered a "case" at the age when she had her first live child; women who were nulliparous at enrollment in AHS-2 were censored at the age when they enrolled. Adjustments were made for marital status (ever married) and educational level (with or without a college degree). Based on this statistical model, we estimated the hazard ratio (HR) for being parous according to the isoflavone intake categories.

When analyzing data from women aged 41-50 who had ended their childbearing, marital status (four groups) and educational level (seven levels) were considered as confounders. A log-binomial model was applied ${ }^{30}$ to estimate the relative risk of ever having given birth to a child or never having been pregnant relative to that in women with, in this population, relatively low ( $<10 \mathrm{mg} /$ day) intake of isoflavones. Stratified analyses within large subsets of the women (eg, never and ever married women, women who never had used alcohol or tobacco, being a vegetarian, or reported problems becoming pregnant) were performed.

The $P$-values are for the test of linear trend over the isoflavone intake categories, scoring from zero to five according to increasing isoflavone intake. Ninety-five percent confidence intervals (CI) for HRs and relative risk estimates were computed. The analyses were performed using SAS 9.3 software (SAS Institute Inc., Cary, NC, USA). ${ }^{31}$

\section{Results}

In the group of women aged 30-50 years (including women from both analytical cohorts), the mean age (standard deviation [SD]) of the women when completing the questionnaire was 42.0 (5.4) years old. Approximately $12 \%$ of the women had never been married. The level of education was high; $51 \%$ had a college degree. Blacks constituted $34 \%$ of the population. The large majority (75\%) had used oral contraceptives for at least a short period of time. Mean age (SD) at menarche was 12.4 (1.5) years. Approximately $74 \%$ had given birth to a live child ( $81 \%$ of ever married and $18 \%$ of never married women), and the mean (SD) number of children in the 8,695 parous women was 2.2 (0.9) and the mean age at first delivery was 26.1 (5.2) years. Approximately $26 \%, 36 \%, 27 \%$, and $11 \%$ of the parous women had their first delivery when they were aged $<23$, $23-27,28-32$, and $>32$, respectively.

Approximately $54 \%$ of the women were vegetarians and $7 \%$ were vegans. The mean intakes in all women of vegetarian meat analogs (not all soy based), soy milk, and tofu/other soybean products were high $(51,81$, and $18 \mathrm{~g}$ per day, respectively). This was reflected in a high intake of soy isoflavones; the mean, median, and interquartile range were $17.9 \mathrm{mg}, 9.1 \mathrm{mg}$, and $21.8 \mathrm{mg}$ per day, respectively. Only $6 \%$ of the women indicated no intake of soy isoflavones. 
Table 1 gives the unadjusted relationships between some variables relevant in reproduction and isoflavone intake in all women (ie, aged 30-50 years). Women with higher soy isoflavone intakes were more likely to have a college degree and to be nulliparous or never have been pregnant, but were the least likely to have used oral contraceptives or used oral contraceptives for most of their reproductive life (for 7 or more years both when aged 20-29 and 30-39 years). There was no relationship between isoflavone intake and age at menarche and the proportion of the women who reported problems becoming pregnant. We found a statistically significant inverse relationship with parity in all women, but not in parous women. Parous women with high isoflavone intake ( $\geq 50 \mathrm{mg}$ isoflavones/day) reported their first delivery approximately 1 year and 4 months later than parous women with low ( $<10 \mathrm{mg}$ isoflavones/day) intake. Thus, the unadjusted results indicate that women with a high isoflavone intake more often report never having been pregnant and being nulliparous and, if parous, had their first delivery relatively late. The relationship with relatively late delivery was explained by education and marital status, however.

The prevalence of ever having been a smoker was low in all groups. The isoflavone intake was inversely related to alcohol intake. A total of $33 \%$ of the women reported that they had ever used alcohol, and among these women approximately $50 \%$ reported use for 5 years or less and with a very low consumption. Nearly half of those who had ever used alcohol stated that they had consumed beer less than monthly; the frequency of wine or liquor consumption was, if anything, even lower. Physical activity was directly related and BMI at age 20 years as well as the frequency of use of caffeinated beverages were inversely related to isoflavone intake. The relationship with BMI at age 20 years was weak, however.

The proportion of vegetarians was much higher (approximately $77 \%$ ) in women with an intake of $\geq 30 \mathrm{mg}$ isoflavones/ day compared to a relatively low intake $(<10 \mathrm{mg} /$ day $)$ (approximately 38\%), and the relationship between isoflavone intake and vegan food pattern was very strong. The

Table I Relationships between soy isoflavone intake and some variables relevant to isoflavone intake and reproduction in the Adventist Health Study-2

\begin{tabular}{|c|c|c|c|c|c|c|c|}
\hline & \multicolumn{6}{|c|}{ Soy isoflavone intake (mg per day) } & \multirow{2}{*}{$\begin{array}{l}P \text { for } \\
\text { trend }\end{array}$} \\
\hline & $0-9$ & $10-19$ & $20-29$ & $30-39$ & $40-49$ & $\geq \mathbf{5 0}$ & \\
\hline Number of women & 6,089 & 1,968 & $\mathrm{I}, 376$ & 812 & 529 & 914 & - \\
\hline Isoflavone intake (mg/day) & $3.7(2.9)$ & $14.7(3.1)$ & $24.6(2.9)$ & $34.5(2.9)$ & $44.8(2.9)$ & $79.3(32.5)$ & - \\
\hline Age at enrollment & $42.0(5.3)$ & $42.1(5.3)$ & $41.9(5.4)$ & $42.0(5.4)$ & $4 I .8(5.3)$ & $4 I .6(5.6)$ & 0.04 \\
\hline$\%$ never married & I3.I (798) & $10.9(215)$ & $11.9(164)$ & $10.3(84)$ & II.5 (6I) & $14.2(130)$ & 0.6 \\
\hline$\%$ with college & $46.5(2,833)$ & $54.5(1,072)$ & $56.8(78 I)$ & $55.4(450)$ & $56.3(298)$ & $59.2(54 I)$ & $<0.001$ \\
\hline$\%$ Black & $35.3(2,134)$ & $32.8(640)$ & $29.5(402)$ & $28.0(226)$ & $33.9(178)$ & $37.4(338)$ & 0.2 \\
\hline Age at menarche & $|2.4|(\mid .54)$ & I2.37 (I.49) & $12.39(\mid .5 \mathrm{I})$ & $12.49(1.52)$ & $12.46(|.5|)$ & $12.40(1.53)$ & 0.6 \\
\hline$\%$ used OCs & $77.3(4,694)$ & $76.6(1,502)$ & $74.8(I, 023)$ & 70.7 (57I) & $69.8(368)$ & $65.9(599)$ & $<0.001$ \\
\hline$\%$ extended OC use* & $3.4(206)$ & $2.0(39)$ & $1.5(20)$ & $1.6(13)$ & I.I (6) & $1.0(9)$ & $<0.001$ \\
\hline$\%$ never pregnant & $17.9(\mid, 089)$ & $19.6(385)$ & I $8.8(258)$ & $20.3(165)$ & I9.I (101) & $22.3(204)$ & 0.002 \\
\hline$\%$ nulliparous & $24.7(1,506)$ & $25.7(506)$ & $25.9(357)$ & $26.5(215)$ & $26.1(138)$ & $29.7(27 I)$ & 0.003 \\
\hline$\%$ problems becoming pregnant & I7.I $(1,032)$ & I6.I (3I5) & I7.8 (243) & $16.4(132)$ & $15.7(82)$ & $15.6(|4|)$ & 0.3 \\
\hline Parity in all women & $1.69(1.27)$ & $1.67(1.29)$ & $1.60(1.21)$ & $1.67(\mathrm{I} .3 \mathrm{I})$ & $1.61(1.25)$ & $\mathrm{I} .54(\mathrm{I} .27)$ & $<0.001$ \\
\hline Parity in parous women & $2.24(0.95)$ & $2.24(0.97)$ & $2.17(0.87)$ & $2.27(0.97)$ & $2.18(0.95)$ & $2.19(0.93)$ & 0.09 \\
\hline Age at first delivery & $25.7(5.2)$ & $26.3(4.9)$ & $26.5(5.0)$ & $26.5(5.0)$ & $26.8(5.2)$ & $27.0(5.3)$ & $<0.001$ \\
\hline$\%$ ever smoked & $7.0(426)$ & $4.6(91)$ & $4.7(65)$ & $3.7(30)$ & $4.9(26)$ & $4.3(39)$ & $<0.001$ \\
\hline$\%$ ever used alcohol & $38.4(2,327)$ & $27.1(533)$ & $27.6(379)$ & $26.6(216)$ & $28.0(148)$ & $25.9(235)$ & $<0.001$ \\
\hline Physical activity (times/week) & $2.2(1.9)$ & $2.4(1.9)$ & $2.5(1.9)$ & 2.7 (1.9) & $2.6(1.9)$ & $2.6(1.9)$ & $<0.001$ \\
\hline BMI $\left(\mathrm{kg} / \mathrm{m}^{2}\right)$ at age 20 & $21.6(3.8)$ & $21.3(3.4)$ & $21.4(3.6)$ & $21.3(3.7)$ & $21.3(3.7)$ & $21.4(4.1)$ & 0.002 \\
\hline$\%$ with monthly use of caffeinated drinks & $49.3(2,956)$ & $32.8(633)$ & $27.6(375)$ & $21.7(173)$ & $19.8(102)$ & $17.5(157)$ & $<0.001$ \\
\hline$\%$ vegetarians & $37.6(2,292)$ & $63.6(1,252)$ & $71.6(985)$ & $77.7(631)$ & $76.6(405)$ & 76.5 (699) & $<0.001$ \\
\hline$\%$ vegans & $2.1(125)$ & $7.0(137)$ & $10.7(147)$ & $15.4(125)$ & $17.8(94)$ & I8.7 (I7I) & $<0.001$ \\
\hline Vegetarian meat analogs (g/day) & $37(38)$ & $62(56)$ & $66(64)$ & $66(58)$ & $69(73)$ & $8 I(8 I)$ & $<0.001$ \\
\hline Tofu/soybean products (g/day) & $3(4)$ & $12(12)$ & $24(19)$ & $38(23)$ & $49(30)$ & $91(74)$ & $<0.001$ \\
\hline Soy milk (g/day) & $9(29)$ & $74(79)$ & $120(1 \mid 2)$ & 153 (139) & $210(171)$ & 380 (333) & $<0.001$ \\
\hline Energy intake (kcal per day) & $\mathrm{I}, 736(702)$ & $\mathrm{I}, 890(689)$ & I,980 (687) & $2,090(702)$ & $2,267(72 \mathrm{I})$ & $2,506(788)$ & $<0.001$ \\
\hline
\end{tabular}

Notes: *Used OCs for 7 or more years both when aged 20-29 years and when aged 30-39 years. Data given as percentages (n) or mean (SD).

Abbreviations: SD, standard deviation; OC, oral contraceptives; BMI, body mass index. 
Spearman's correlation coefficients between soy isoflavone intake (categorized in Table 1) and being vegetarian or vegan were 0.34 and 0.23 , respectively. The correlation coefficient between soy isoflavone intake (categorized as in Table 1) and the intake of soy milk was 0.70 , with tofu/other soybean products 0.71 , and with the intake of vegetarian meat analogs (not all soy based) 0.29 . There was a positive relationship between the isoflavone intake and the energy intake.

Analyses restricted to the 4,476 women who were aged 30-40 years at enrollment and adjusted for marital status (ever/never married) and level of education demonstrated an inverse relationship between isoflavone intake and the probability of never giving birth to a live child. However, the association was clearly attenuated by attained age (stronger relationship in younger women). Thus, we present the estimated HRs at age 26 years, the mean age at first delivery in parous women (Table 2 ). A statistically significant $(P=0.003)$ inverse relationship was found. Further analyses (not shown) indicated that the relationship was statistically significant $(P \leq 0.05)$ at all ages below 28. Adjustments for race, ever use of oral contraceptives, body mass at age 20 years, or restricting the analyses to ever married women $(n=3,681)$ only marginally influenced the results displayed in Table 2 . If anything, the relationships were strengthened when adjusted for the energy intake or restricted to women who never had used alcohol or tobacco. When stratified for being a vegetarian or not, the linear relationship was, however, only found in nonvegetarians. Although statistically significant $(P<0.05)$ in both women who did not report problems becoming pregnant and women who reported such problems, the relationship was stronger in the latter group of women $(P$-value for interaction $=0.08)$.

Table 2 Associations between soy isoflavone intake ( $\mathrm{mg}$ per day) and fertility (at least one live child) estimated at age 26 years in the Adventist Health Study-2

\begin{tabular}{lll}
\hline $\begin{array}{l}\text { Isoflavone intake } \\
(\mathbf{m g} / \text { day })\end{array}$ & $\begin{array}{l}\text { Number of women/ } \\
\text { parous women }\end{array}$ & $\begin{array}{l}\text { Hazard ratio } \\
(\mathbf{9 5 \%} \mathrm{Cl}) \\
\text { at age 26 years }\end{array}$ \\
\hline$<10$ & $2,28 I / I, 569$ & 1.0 \\
$10-19$ & $742 / 512$ & $0.92(0.83,1.02)$ \\
$20-29$ & $526 / 358$ & $0.93(0.84,1.04)$ \\
$30-39$ & $320 / 220$ & $0.86(0.74,1.00)$ \\
$40-49$ & $221 / 152$ & $0.93(0.78,1.10)$ \\
$50+$ & $386 / 259$ & $0.83(0.72,0.96)$ \\
All & $4,476 / 3,070$ & \\
$P$-value for linear trend & & 0.003 \\
\hline
\end{tabular}

Notes: Adjusted for educational level and marital status. Women aged 30-40 years when completing the lifestyle questionnaire.

Abbreviation: $\mathrm{Cl}$, confidence interval.
Table 3 Associations between soy isoflavone intake ( $\mathrm{mg}$ per day) and fertility (at least one live child) in the Adventist Health Study-2

\begin{tabular}{lll}
\hline $\begin{array}{l}\text { Isoflavone intake } \\
(\mathrm{mg} / \mathrm{day})\end{array}$ & $\begin{array}{l}\text { Number of } \\
\text { women/parous } \\
\text { women }\end{array}$ & $\begin{array}{l}\text { Estimated relative } \\
\text { risk }(95 \% \mathrm{Cl}) \text { for } \\
\text { giving birth to at } \\
\text { least one live child }\end{array}$ \\
\hline$<10$ & $3,808 / 3,014$ & 1.0 \\
$10-19$ & $1,226 / 950$ & $0.99(0.96,1.02)$ \\
$20-29$ & $850 / 661$ & $0.99(0.96,1.02)$ \\
$30-39$ & $492 / 377$ & $0.97(0.93,1.02)$ \\
$40-49$ & $308 / 239$ & $0.98(0.93,1.03)$ \\
$50+$ & $528 / 384$ & $0.96(0.92,1.01)$ \\
All & $7,212 / 5,625$ & \\
$P$-value for linear trend & & 0.05 \\
\hline
\end{tabular}

Notes: Adjusted for age when completing the lifestyle questionnaire, educational level and marital status. Women aged 4I-50 years when completing the lifestyle questionnaire.

Abbreviation: $\mathrm{Cl}$, confidence interval.

Table 3 gives the results from the analyses including the 7,212 women aged 41-50 years, women who for all practical purposes have ended their childbearing period. A total of $78 \%$ of these women were parous. A linear inverse relationship $(P=0.05)$ was seen between isoflavone intake and the probability of giving birth to at least one child with $1 \%$ reduced risk per unit (basically $10 \mathrm{mg}$ per day) increase in isoflavone intake. Women who had a high ( $\geq 40 \mathrm{mg} /$ day) intake had a $3 \%$ (95\% CI: 0,7$)$ lower risk of being parous than women with a low $(<10 \mathrm{mg} /$ day $)$ isoflavone intake.

The associations were found in both ever and never married women. Adjustment for race, use of oral contraceptives, physical activity, BMI at age 20 years, monthly or more frequent use of caffeinated beverages, and ever having smoked or used alcohol in concert did not change the findings more than marginally. The relationship between the isoflavone intake and nulliparity was, if anything, stronger in the 4,884 women who never had used alcohol or tobacco ( $P=0.01$ ). Adjustments for vegetarianism tended to somewhat strengthen the association, and there was no interaction with being a vegetarian. The relationship was statistically significant in women who reported problems in becoming pregnant, whereas essentially no relationship was found in other women; a formal test for interaction was statistically significant $(P=0.01)$. In women who reported problems becoming pregnant, a one unit (10 $\mathrm{mg}$ per day) increase in isoflavone intake was associated with a 4\% (95\% CI: 1, 6) higher nulliparity risk.

The mean (SD) parity and age at first delivery in parous women was 2.3 (0.9) children and 26.1 (5.2) years, respectively, among women aged $41-50$ years. The isoflavone intake, after adjustments for age, education and marital status, 
was not associated with parity or age at first delivery when the analysis was confined to parous women.

In accordance with the findings for nulliparity, we also observed a linear direct relationship $(P=0.03)$ between the isoflavone intake and never having been pregnant (Table 4). Women who had a relatively high intake (40 $\mathrm{mg}$ isoflavone per day or above) had an approximately $13 \%$ (95\% CI: 2,26$)$ higher risk of never having been pregnant than women with a relatively low intake ( $<10 \mathrm{mg} /$ day). In contrast to the findings for nulliparity, adjustments for being a vegetarian reduced the strength of the relationship and it was not statistically significant after adjustments. There was no interaction with being a vegetarian, however.

Similarly to the relationships with nulliparity, we found indications of a stronger relationship in women who reported problems becoming pregnant than in other women $(P$-value for interaction $=0.08)$. In the former group of women, a statistically significant $(P=0.01)$ positive relationship between the isoflavone intake and never having been pregnant was found, with a 9\% (95\% CI: 2, 17) increased risk per unit (10 mg per day) increase in isoflavone intake. In women who did not report problems becoming pregnant, a weaker relationship $(P=0.06)$ was found, with a $2 \%(95 \% \mathrm{CI}: 0,5)$ increased risk per unit (10 mg per day) increase in isoflavone intake.

\section{Discussion}

The main finding of this study is that women who in a Western context have a very high isoflavone intake have a somewhat increased risk of never having been pregnant or given birth to a live child. The results suggest that when the isoflavone intake exceeds approximately $40 \mathrm{mg}$ per day, the overall lifetime risk of never becoming pregnant increased by $13 \%$

Table 4 Associations between soy isoflavone intake (mg per day) and never having been pregnant in the Adventist Health Study-2

\begin{tabular}{lll}
\hline $\begin{array}{l}\text { Isoflavone intake } \\
(\mathbf{m g} / \text { day })\end{array}$ & $\begin{array}{l}\text { Number of women/ } \\
\text { never pregnant } \\
\text { women }\end{array}$ & $\begin{array}{l}\text { Estimated relative } \\
\text { risk }(95 \% \mathrm{CI}) \\
\text { for never been } \\
\text { pregnant }\end{array}$ \\
\hline$<10$ & $3,808 / 558$ & 1.0 \\
$10-19$ & $1,226 / 208$ & $1.14(1.03,1.26)$ \\
$20-29$ & $850 / 129$ & $0.98(0.86,1.12)$ \\
$30-39$ & $492 / 85$ & $1.10(0.95,1.27)$ \\
$40-49$ & $308 / 52$ & $1.11(0.92,1.33)$ \\
$50+$ & $528 / 103$ & $1.15(1.02,1.29)$ \\
All & $7,212 / 1,135$ & 0.03 \\
$P$-value for linear trend & & \\
\hline
\end{tabular}

Notes: Adjusted for age when completing the lifestyle questionnaire, educational level, and marital status. Women aged 4I-50 when completing the lifestyle questionnaire.

Abbreviation: $\mathrm{Cl}$, confidence interval. and that of ever giving birth to a live child was reduced by approximately $3 \%$. The associations were consistently found to be stronger in women who reported having had difficulties in becoming pregnant (1 straight year or more without success to become pregnant). To our knowledge, this is the first study which has examined the possible relationship between isoflavone intake and fertility within a diverse, non-clinical, population.

One major limitation in our study is that we are not able to distinguish with certainty between involuntary and voluntary childlessness. Both may be related to the isoflavone intake. If high isoflavone intake increases the risk of longer cycle length ${ }^{11}$ and/or uterine pathology (fibroids, endometrial growth, etc), ${ }^{14-16}$ this may hamper fertility. It is also possible that women who differ with regard to the isoflavone intake also differ with regard to other lifestyle and sociological factors related to childbearing other than those that we have been able to adjust for. The stronger relationship between isoflavone intake and the proportion who report to be nulliparous or never having been pregnant in women who had problems becoming pregnant does, however, suggest a biological impact of isoflavones.

The isoflavone intake (mean intake $17.9 \mathrm{mg}$ /day) was very high compared to other Western populations (typically $<3 \mathrm{mg} /$ day). ${ }^{5}$ The large intake and large variation in intake in our study made it possible to examine the impact of high intake of isoflavones on childbearing. The intake of isoflavones was based on information about current food habits. As discussed elsewhere, ${ }^{29}$ there are considerable uncertainties related to the isoflavone content of the foods. This misclassification will, however, be unrelated to nulliparity; it has introduced non-differential misclassification and thus attenuated the associations.

Another limitation is that for many women there may be several years between age at first delivery and completing the questionnaire; misclassification with regard to dietary intake before and during childbearing has therefore undoubtedly taken place. However, the women included were all current members of the Adventist church who also indicated that they had been Adventists when they were 15-25-years-old. Therefore, the majority of them have probably not made dramatic changes in their lifestyle - including dietary habits during the childbearing years. An indication of adherence to this lifestyle is that only $6 \%$ of the women had ever smoked cigarettes.

Unpublished observations, based on a retrospective enquiry relating to the past decade of life, indicate a tendency in this Adventist population to change their dietary 
habits in a vegetarian direction (and thus increasing isoflavone intake) with advancing age. However, only a very weak (and actually inverse) cross-sectional relationship was found between the isoflavone intake and age in our study sample. A direct relationship between isoflavone intake and nulliparity will be found if nulliparous women increased the intake of soy products and isoflavone to a greater degree than parous women, eg, that women with problems becoming pregnant increased their intake of soy product because they believed that these products would enhance fertility. We have no indications that this has been the case as there were no relationships between the isoflavone intake and the proportion who reported problems becoming pregnant (Table 1). This was the case in both women aged 30-40 and those aged $41-50$ years.

In order to address the problem of the time lag between childbearing and the reported dietary habits, we investigated the relationship in two different groups of women, 30-40-year-olds and 41-50-year-olds. In women aged 30-40 years, the mean duration between the first delivery and completion of the questionnaire was approximately 10 years. However, women may still give birth to their first child at later ages. Therefore, we also included a group of women aged 41-50 years who for all practical purposes have ended their childbearing when completing the questionnaire. For these women, the time period between childbearing and information on dietary habits may have been quite long (a mean of approximately 20 years). However, results from both analytical cohorts indicated that a high isoflavone intake increased the likelihood of nulliparity.

The HRs given in Table 2 are estimated from the Cox regression model, essentially following the women from the age of 14 years (as detailed in the Material and methods section). Thus, there is no contradiction in estimating the HRs (eg, at age 26 years) even though no women were below age 30 years at enrollment.

We consider it a strength of this study that it is conducted in a population with extensive information on dietary habits and where the possible impact of alcohol and smoking can be virtually excluded. Alcohol and caffeine consumption have been studied in relation to possible impact on fertility (with mixed results). ${ }^{32-34}$ Smoking reduces fertility and has, as it is well known, a number of adverse effects on pregnancy outcomes. ${ }^{35}$ The women included in our study had very low prevalence of ever smoking (6\%) and also a low consumption of alcohol; only $33 \%$ of the women had ever used alcohol and the alcohol intake among most of the ever-users was negligible during the years they did use alcohol (less than monthly).
Women who differ with regard to diet also may differ with regard to the other variables known to have an impact on childbearing. We adjusted for not only the most important predictors for childbearing, in particular marital status and educational level, but also for race (Black versus non-Black), use of oral contraceptives, BMI at age 20 years, ${ }^{22,23}$ physical activity, and monthly or more frequent use of caffeinated beverages, in separate analyses. Furthermore, stratified analyses including only women who had never smoked cigarettes or used alcohol confirmed our findings from analyses in all women. One possible unmeasured confounder is the male partner's diet. If male diet influences fertility, this may have had an impact on the associations as the spouses often conform to the same dietary pattern.

The results of the analyses based on the two populations aged 30-40 and 41-50 years, respectively, seem only to differ significantly at one point, ie, with regard to a possible interaction with being a vegetarian. However interesting, we have no obvious explanation for the seemingly different results; given the somewhat exploratory nature of our analyses and the many statistical tests conducted, we do not believe that this apparent inconsistency deserves much emphasis at this point.

\section{Conclusion}

In summary, we find that women with a high intake of isoflavones have an increased risk of never becoming pregnant and being childless when they are at an age where they are at the end of their childbearing period (aged $41-50$ years). Both sociological and biological explanations may be put forward to explain our findings. The stronger relationship in women who reported problems becoming pregnant is, in this context, interesting. However, we call for further studies, preferably prospective studies, to either refute or confirm our findings that isoflavones have a significant impact on childbearing.

\section{Acknowledgments}

This work was supported by grants from the National Cancer Institute (5R01 CA094594 and 5U01 CA152939). The Adventist Health study research has been approved by the Loma Linda University Institutional Review Board.

\section{Disclosure}

The authors report no conflicts of interest in this work.

\section{References}

1. Patisaul HB, Jefferson W. The pros and cons of phytoestrogens. Front Neuroendocrinol. 2010;31(4):400-419. 
2. Baber R. Phytoestrogens and post reproductive health. Maturitas. 2010;66(4):344-349.

3. Messina M. Insights gained from 20 years of soy research. $J$ Nutr. 2010;140(12):2289S-2295S.

4. Cederroth CR, Nef S. Soy, phytoestrogens and metabolism: A review. Mol Cell Endocrinol. 2009;304(1-2):30-42.

5. Messina M. A brief historical overview of the past two decades of soy and isoflavone research. J Nutr. 2010;140(7):1350S-1354S.

6. de Kleijn MJ, van der Schouw YT, Wilson PW, et al. Intake of dietary phytoestrogens is low in postmenopausal women in the United States: the Framingham study (1-4). J Nutr. 2001;131(6): 1826-1832.

7. Carmichael SL, Gonzalez-Feliciano AG, Ma C, Shaw GM, Cogswell ME. Estimated dietary phytoestrogen intake and major food sources among women during the year before pregnancy. Nutr J. 2011;10:105.

8. Jefferson WN, Williams CJ. Circulating levels of genistein in the neonate, apart from dose and route, predict future adverse female reproductive outcomes. Reprod Toxicol. 2011;31(3):272-279.

9. Jefferson WN. Adult ovarian function can be affected by high levels of soy. J Nutr. 2010;140(12):2322S-2325S.

10. Cederroth CR, Zimmermann C, Nef S. Soy, phytoestrogens and their impact on reproductive health. Mol Cell Endocrinol. 2012;355(2): 192-200.

11. Hooper L, Ryder JJ, Kurzer MS, et al. Effects of soy protein and isoflavones on circulating hormone concentrations in pre- and postmenopausal women: a systematic review and meta-analysis. Hum Reprod Update. 2009;15(4):423-440.

12. Jefferson WN, Patisaul HB, Williams C. Reproductive consequences of developmental phytoestrogen exposure. Reproduction. 2012;143(3): 247-260.

13. Tempfer CB, Froese G, Heinze G, Bentz EK, Hefler LA, Huber JC. Side effects of phytoestrogens: a meta-analysis of randomized trials. Am J Med. 2009;122(10):939-946. e9.

14. Amsterdam A, Abu-Rustum N, Carter J, Krychman M. Persistent sexual arousal syndrome associated with increased soy intake. J Sex Med. 2005;2(3):338-340.

15. Chandrareddy A, Muneyyirci-Delale O, McFarlane SI, Murad OM. Adverse effects of phytoestrogens on reproductive health: a report of three cases. Complement Ther Clin Pract. 2008;14(2): $132-135$.

16. Unfer V, Casini ML, Costabile L, Mignosa M, Gerli S, Di Renzo GC. Endometrial effects of long-term treatment with phytoestrogens: a randomized, double-blind, placebo-controlled study. Fertil Steril. 2004;82(1):145-148. Quiz 265.

17. Cohain JS. Daily intake of isoflavones of $>0.07 \mathrm{~g}$ associated with endometrial bleeding. BJOG. 2010;117(4):500-501.

18. Ollberding NJ, Lim U, Wilkens LR, et al. Legume, soy, tofu, and isoflavone intake and endometrial cancer risk in postmenopausal women in the multiethnic cohort study. J Natl Cancer Inst. 2012;104(1): 67-76.

19. Myung SK, Ju W, Choi HJ, Kim SC. Soy intake and risk of endocrine-related gynaecological cancer: a meta-analysis. BJOG. 2009;116(13):1697-1705.
20. Unfer V, Casini ML, Gerli S, Costabile L, Mignosa M, Di Renzo GC. Phytoestrogens may improve the pregnancy rate in in vitro fertilizationembryo transfer cycles: a prospective, controlled, randomized trial. Fertil Steril. 2004;82(6):1509-1513.

21. Butler TL, Fraser GE, Beeson WL, et al. Cohort profile: The Adventist Health Study-2 (AHS-2). Int J Epidemiol. 2008;37(2):260-265.

22. Jacobsen BK, Knutsen SF, Oda K, Fraser GE. Obesity at age 20 and the risk of miscarriages, irregular periods and reported problems of becoming pregnant: the Adventist Health Study-2. Eur J Epidemiol. 2012;27(12):923-931.

23. Jacobsen BK, Knutsen SF, Oda K, Fraser GE. Body mass index at age 20 and subsequent childbearing: The Adventist Health Study-2. $J$ Womens Health (Larchmt). 2013;22(5):460-466.

24. Jaceldo-Siegl K, Knutsen SF, Sabaté J, et al. Validation of nutrient intake using an FFQ and repeated $24 \mathrm{~h}$ recalls in black and white subjects of the Adventist Health Study-2 (AHS-2). Public Health Nutr. 2010;13(6):812-819.

25. Jaceldo-Siegl K, Fan J, Sabaté J, et al. Race-specific validation of food intake obtained from a comprehensive FFQ: the Adventist Health Study-2. Public Health Nutr. 2011;14(11):1988-1997.

26. Orlich MJ, Singh PN, Sabaté J, et al. Vegetarian dietary patterns and mortality in Adventist Health Study 2. JAMA Intern Med. 2013;173(13): 1230-1238.

27. Schakel SK. Maintaining a nutrient database in a changing marketplace: keeping pace with changing food products-a research perspective. J Food Comp Anal. 2001;14(3):315-322.

28. Willett W. Food frequency methods. In: Willett W, editor. Nutritional Epidemiology. 2nd ed. New York: Oxford University Press; 2008: 74-100.

29. Jaceldo-Siegl K, Fraser GE, Chan J, Franke A, Sabaté J. Validation of soy protein estimates from a food-frequency questionnaire with repeated 24-h recalls and isoflavonoid excretion in overnight urine in a Western population with a wide range of soy intakes. Am J Clin Nutr. 2008;87(5):1422-1427.

30. McNutt LA, Wu C, Xue X, Hafner JP. Estimating the relative risk in cohort studies and clinical trials of common outcomes. Am J Epidemiol. 2003;157(10):940-943.

31. SAS Institute Inc. SAS/STAT User's Guide, Version 9. Cary, NC:SAS Institute; 2004.

32. Chavarro JE, Rich-Edwards JW, Rosner BA, Willett WC. Caffeinated and alcoholic beverage intake in relation to ovulatory disorder infertility. Epidemiology. 2009;20(3):374-381.

33. Jones KL. The effects of alcohol on fetal development. Birth Defects Res C Embryo Today. 2011;93(1):3-11.

34. Peck JD, Leviton A, Cowan LD. A review of the epidemiologic evidence concerning the reproductive health effects of caffeine consumption: a 2000-2009 update. Food Chem Toxicol. 2010;48(10):2549-2576.

35. Rogers JM. Tobacco and pregnancy: overview of exposures and effects. Birth Defects Res C Embryo Today. 2008;84(1):1-15.
International Journal of Women's Health

\section{Publish your work in this journal}

The International Journal of Women's Health is an international, peerreviewed open-access journal publishing original research, reports, editorials, reviews and commentaries on all aspects of women's healthcare including gynecology, obstetrics, and breast cancer. The manuscript management system is completely online and includes

\section{Dovepress}

a very quick and fair peer-review system, which is all easy to use. Visit http://www.dovepress.com/testimonials.php to read real quotes from published authors. 